\title{
The Growth of Large Single Crystal Sheets with the (100) [011] Orientation from Electrolytic Iron
}

\author{
By Tomoyuki Takeuchi*
}

\begin{abstract}
In order to prepare large single crystal sheets from an electrolytic iron, the effect of roll textures on the growth of large crystals by a strain-anneal technique has been investigated. The results show that the preferred orientation of large grains grown by the strain-anneal method is approximately the same as the roll texture, and. that the large crystals free from island grains left on the sheet surface has the (100) plane in the sheet surface. It is necessary to prepare a sharp (100) [011] roll texture for the growth of large erystals (1 2 mm in thickness and about $45 \times 300 \mathrm{~mm}^{2}$ in the sheet surface) with the (100) [011] orientation by the strain-anneal method. This roll texture was produced by cross-rolling in the final stage of rolling process. Attempts to grow crystals with other orientations ended in a failure.
\end{abstract}

(Received June 21, 1965)

\section{Introduction}

Preparation of large iron single crystals from which many specimens can be cut out is desirable for studying the plastic properties of iron, such as temperature and strain rate dependences of yield stress. Edward and Pfeil(1) have reported, for the first time, a systematic investigation on the growth of large crystals of iron with a thickness of about $3 \mathrm{~mm}$ by the strainanneal technique. Honda and Kaya ${ }^{(2)}$ have produced large crystals with a thickness of $6 \mathrm{~mm}$ by using a similar material and technique. These techniques employed the final annealing in the furnace having a constant temperature just below the $\alpha-\gamma$ transformation temperature. Gensamer and $\mathrm{Mehl}^{(3)}$ have produced large crystals by gradually lowering the rods $13 \mathrm{~mm}$ in diameter into the furnace. The raw materials used in the above investigations ${ }^{(1)-(3)}$ were decarburized mild steels containing about 0.4 percent manganese.

The technique for the growth of a single crystal with a controlled orientation from a seed crystal was developed by Fujiwara and Tatsumoto ${ }^{(4)}$ and Dohi and Yamashita. ${ }^{(5)}$ This method has been applied to the growth of single crystals of silicon-iron by Dunn and Nonken ${ }^{(6)}$, and to that of large single crystals of iron $\left(2 \times 25 \times 300 \mathrm{~mm}\right.$ in size) by Stein and Low ${ }^{(7)}$.

Recrystallization behaviours of metals and alloys are

* National Research Institute for Metals, Nakameguro Meguro-ku Tokyo, Japan.

(1) C.A. Edward and L.B. Pfeil: J. Iron Steel Inst., 109 (1924), 129.

(2) K. Honda and S. Kaya: Sci. Rep. Tohoku Univ., 15 (1926), 721.

(3) M. Gensamer and R.F. Mehl: Trans. AIME, 131 (1938), 372.

(4) T. Fujiwara and E. Tatsumoto: J. Sci. Hiroshima Univ., A, 12 (1942), 169.

(5) S. Dohi and T. Yamashita: Memoirs of the Defence Academy, (Yokosuka, Japan) 1 (1957), 13.

(6) C.G. Dunn and G.C. Nonken: Metal Progress, 64 (6) (1953), 71.

(7) D.F. Stein and J.R. Low Jr.: Trans AIME, 221 (1961), 744. very sensitive to very small amounts of impurities and cold roll textures. Therefore any successful process for the growth of large crystals in various iron containing different amounts of impurities does not seem to have been established. The purpose of the present work was to produce large single crystal sheets from high purity electrolytic iron by a strain-anneal method. The annealing temperature and the amount of critical strain before the growth of a crystal should be regarded as very important factors. However, investigations of these factors would be significant only in case the materials have adequate impurities or roll textures for the growth of large crystals. The present report describes a systematic investigation of the effects of the working processes on the growth of crystals by a strain-anneal method, and a reproducible procedure to prepare large single crystal sheets with the (100) plane in the sheet surface and the [011] axis in the growth direction.

\section{Experimental Procedure}

The starting material was an electrolytic iron of high purity grade obtained from Showa Electrochemical Industry Ltd. Chemical analysis of the material after the growth of single crystals shows the following impurities in weight percent:

$$
\begin{array}{ccccccc}
\mathrm{C} & \mathrm{Si} & \mathrm{Mn} & \mathrm{P} & \mathrm{S} & \mathrm{Cu} & \mathrm{Al} \\
0.002 & 0.001 & 0.001 & 0.001 & 0.004 & 0.001 & 0.001 \\
\mathrm{O} & \mathrm{N} & & & & & \\
0.0154 & 0.0003 . & & & & &
\end{array}
$$

The impurity content of the starting material was substantially the same as the above composition except for carbon $(0.008)$ and oxygen $(0.036)$. The electrolytic iron weighing $7 \mathrm{~kg}$ was melted each timein a high frequency induction furnace under the hydrogen pressure of $100 \mathrm{mmHg}$, and then cast in vacuum. Some experiments in section III were carried out using a $10-\mathrm{kg}$ ingot obtained from a different melting process, and the impurity content after the growth of single crystals was found to be nearly the same as above material except for oxygen 
(0.0063), sulfur (0.005), and phosphor (0.002).

All the ingots were hot forged at about $800^{\circ} \mathrm{C}$ and machined into slabs $25 \mathrm{~mm}$ in thickness and $150 \mathrm{~mm}$ or $100 \mathrm{~mm}$ in breadth. The purpose of the present investigation was to examine the subsequent working processes.

The iron used here could not be rolled at room temperature in the annealed or hot worked condition except for the sheets with a thickness less than a few milimeters. The lowest temperature at which the slabs $25 \mathrm{~mm}$ in thickness could be rolled without cracking was $550 \sim 600^{\circ} \mathrm{C}$. This temperature was lower in the sheets of smaller thickness. The word, rolled, in this report means that a sheet was rolled after heating at a temperature free from cracking in a rolling mill, and that the temperature of the sheet during the rolling reduction was gradually lowered down to room temperature. The rates of rolling reduction were $1 \mathrm{~mm}$ per pass at a thickness of $25 \sim 10$ $\mathrm{mm}, 0,5 \mathrm{~mm}$ at $10 \sim 5 \mathrm{~mm}$, and $0.2 \sim 0.1 \mathrm{~mm}$ at $5 \sim 1$ $\mathrm{mm}$.

The size of the sheets used for the growth of large crystals were $1 \sim 2 \mathrm{~mm}$ in thickness, $40 \sim 50 \mathrm{~mm}$ in breadth, and $300 \sim 450 \mathrm{~mm}$ in length. The processes after cutting the sheets were as follows: (1) Annealing in dry hydrogen at a temperature in the range of $750 \sim 890^{\circ} \mathrm{C}$, (2) straining $3 \sim 6$ percent in tension, (3) annealing in a temperature gradient furnace to make seed crystals, (4) cutting and rotation of a seed crystal to a desired orientation, and (5) growth of the seed crystal in a temperature gradient furnace.

The cross section of the temperature gradient furnace used in the present investigation is shown in Fig. 1. The steel vessel was filled with dry hydrogen of about one atmospheric pressure. The size of the water cooled copper slit was $55 \times 1.5 \mathrm{~mm}$ or $55 \times 2.5 \mathrm{~mm}$. The temperature gradient detected by a spot welded thermocouple on a sheet of iron $1 \mathrm{~mm}$ in thickness at $800^{\circ} \mathrm{C}$ was about $35^{\circ} \mathrm{C} / \mathrm{cm}$ when the maximum temperature of the furnace was held at $865^{\circ} \mathrm{C}$. The position of the maximum temperature was at about $10 \mathrm{~cm}$ below the cold slit. The lowering speed of a sheet into the furnace was fixed at a speed of $2 \mathrm{~cm} / \mathrm{hr}$ in the present work.

It is considerably time-consuming to anneal every sheet produced by various working processes in the temperature gradient furnace. As a simple method to test the possibility to grow sheets, produced by various working processes, into large crystals, the final annealing in the temperature gradient furance was substituted by the annealing in a constant temperature furance. For this purpose, the test sheets $20 \sim 25 \mathrm{~mm}$ in breadth and $150 \sim 200 \mathrm{~mm}$ in length were used. The final annealing of the large crystals in the temperature gradient furnace was carried out only for the sheets that satisfied the following conditions under the macroscopic observation after the final annealing in a constant temperature furnace at $850^{\circ} \mathrm{C}$ for 3 hours in hydrogen:

(1) There exist large grains with the diameter of about $20 \mathrm{~mm}$ or more , free from island grains left on the sheet surface.

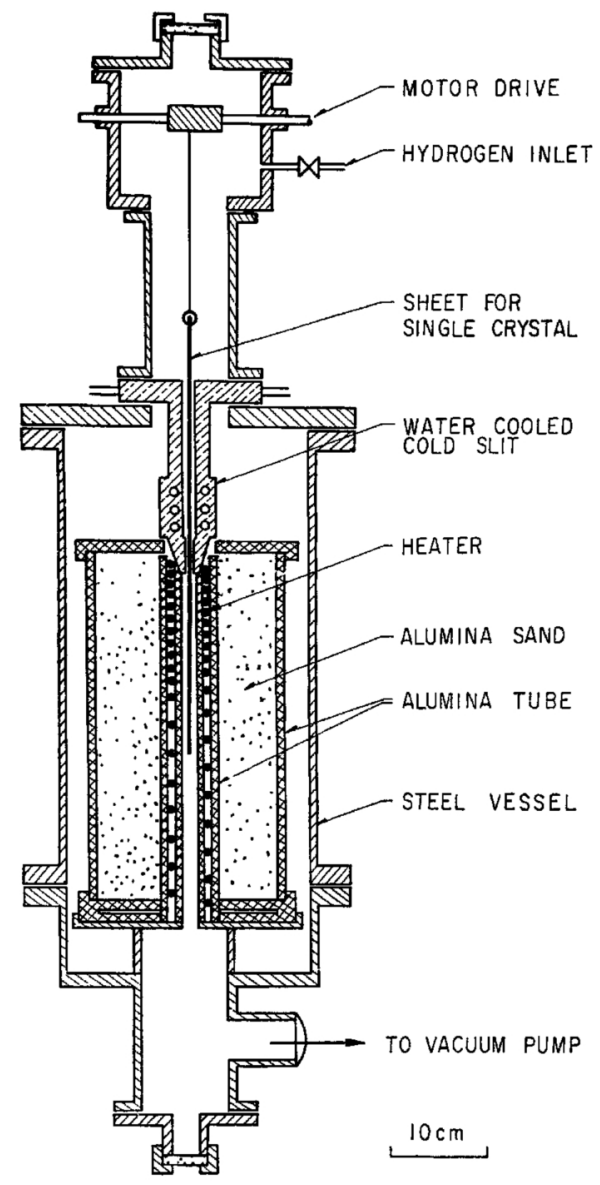

Fig. 1 Cross section of the temperature gradient furacne.

(2) The shapes of large grains on the top surface coinside with the bottom surface.

This condition will be called hereafter the condition (A). The sheets produced by a working process which satisfied the condition (A) did not necessarily grow into the large crystals intended after the annealing in the temperature gradient furnace.

The textures in the middle layers of the rolled sheets and recrystallized sheets were observed by the $\mathrm{X}$-ray pole figure method with the use of the Fe- $\mathrm{Ka}$ ray and $\{220\}$ poles reflected from the chemically polished specimen surface. The crystal orientations of large grains in the test sheets after the final annealing and the seed crystals were determined by the light figure technique ${ }^{(8)},(9)$. The etching reagent used for the light figure technique was the 25 pct $\mathrm{HNO}_{3}-75$ pet $\mathrm{H}_{2} \mathrm{O}$ solution, which develops the $\{100\}$ planes on the crystal surfaces.

\section{Effect of Rolling Reduction}

Early experiences in the present work showed that the cold rolled sheets produced by an ordinary process (rolled the hot rolled sheets $3 \mathrm{~mm}$ thick to the thickness of $1 \mathrm{~mm}$ ) did not grow into the large crystals of intended size after strain-annealing. This result suggested that the growth of large crystals be impossible in the sheets which have improper roll textures

(8) C.S. Barrett and L.H. Levenson: Trans. ALME, 137 (1940), 76.

(9) M. Yamamoto: J. Japan Inst. Metals, 5 (1941), 324. 


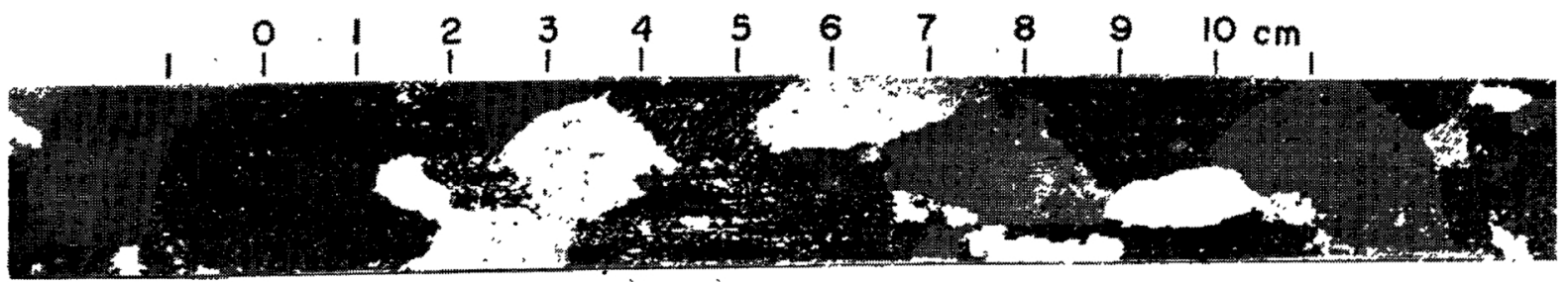

Photo. 1 A strain-annealed test sheet, which was rolled from $25 \mathrm{~mm}$ to $1 \mathrm{~mm}$ in thickness without intermediate annealing, annealed at $850^{\circ} \mathrm{C}$ for 3 hours, strained by 5.5 percent and annealed finally at $850^{\circ} \mathrm{C}$ for 20 hours. $\times 1$

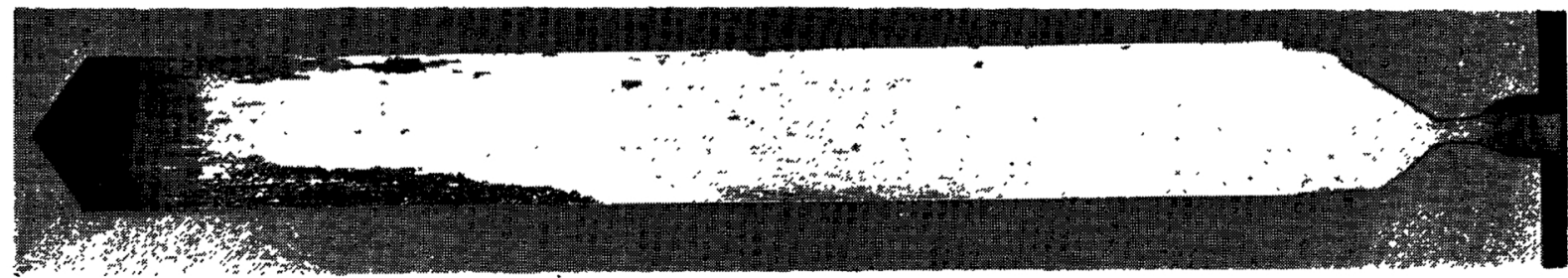

[Photo. 2 An iron single crystal sheet of $(100)$ [011] orientation, which had the same process as the test sheet in Photo. 1 except the final annealing in the temperature gradient furnace. $\times 1 / 3$.

for the growth of large crystals by strain-annealing. Then the effect of the final rolling reduction ratio on the growth of large crystals was investigated as the first step.

A slab $25 \mathrm{~mm}$ in thickness was rolled into sheets of various thickness. The sheets with a thickness of 25 , 10,5 , and $3 \mathrm{~mm}$ were annealed at $800^{\circ} \mathrm{C}$ for 30 minutes and rolled to the thickness of $1 \mathrm{~mm}$. The test sheets cut from these sheets were annealed at $800^{\circ} \mathrm{C}$, and extended by $5 \sim 9$ percent at the speed of $3 \mathrm{~mm} / \mathrm{min}$ $\left(\sim 3 \times 10^{-4} \mathrm{sec}^{-1}\right)$ until the entire sheet surface was covered by Lüders bands. Macroscopic observations of the test sheets after the final annealing at $850^{\circ} \mathrm{C}$ for 3 hours showed that the sheet which was rolled directly to the thickness of $1 \mathrm{~mm}$ without intermediate annealing had the largest grain size.

The effect of the primary annealing temperature before the critical strain was observed in the sheets rolled from the thickness of $25 \mathrm{~mm}$ to $1 \mathrm{~mm}$. As a result, the annealing at $850^{\circ} \mathrm{C}$ was known to satisfy the condition (A). A macrophotograph of the test sheet is shown in Photo. 1. The white grains in this photograph had nearly the (100) plane in the sheet surface, and the black grains had the planes with a deviation of 30 40 degrees from the (100) plane. The grains with the (100) plane in the sheet surface were almost free from island grains left on the surface, and the grain which deviated considerably from this orientation had many island grains on the sheet surface.

From the experimental results of the test sheets, it was considered that large single crystal sheets with the (100) plane in the sheet surface, which were free from island grains, could be grown in the sheets with the rolling reduction of 96 percent. Several groups of the sheets which were rolled from the slabs $25 \mathrm{~mm}$ to $1 \mathrm{~mm}$ in thickness without intermediate anneal were tried to grow large crystals in the temperature gradient furnace. Only one group of the sheets was grown into large crystals with the (100) plane in the sheet surface and the [011] axis in the direction of growth. The largest crystal is shown in Photo. 2. The other groups of the sheets produced by the same process were not recrystallized into large crystals with the (100) [011] orientation. The large crystals of the other orientations were able to grow in the sheets of all the groups, but they had many island grains left on the sheet surface. Accordingly, it was concluded that the sheets produced by a high rolling reduction had a character to grow into large crystals with the orientation (100) [011], but the roll textures in these sheets were not satisfactory as a reproducible procedure.

The variation of the texture during each working process was observed. The roll texture of a sheet rolled from $25 \mathrm{~mm}$ to $1 \mathrm{~mm}$ in thickness without intermediate anneal is shown in Fig. 2. This is the standard roll texture of iron in the stable end orientation. Fig. 3 is the recrystallized texture after the primary anneal-

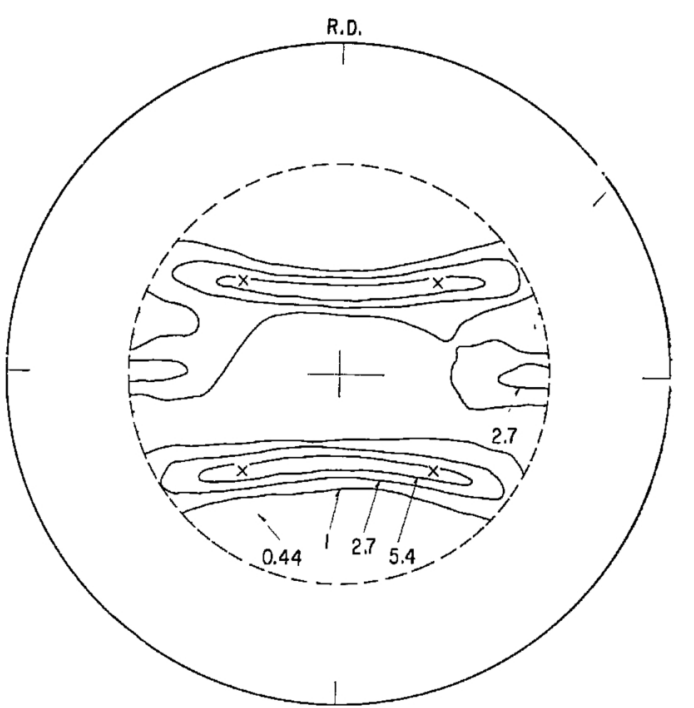

Fig. 2 (110) pole figure of a sheet rolled from $25 \mathrm{~mm}$ to $1 \mathrm{~mm}$ in thickness without intermediate annealing. Intensities are expressed as multiples of random intensity of iron powder. 


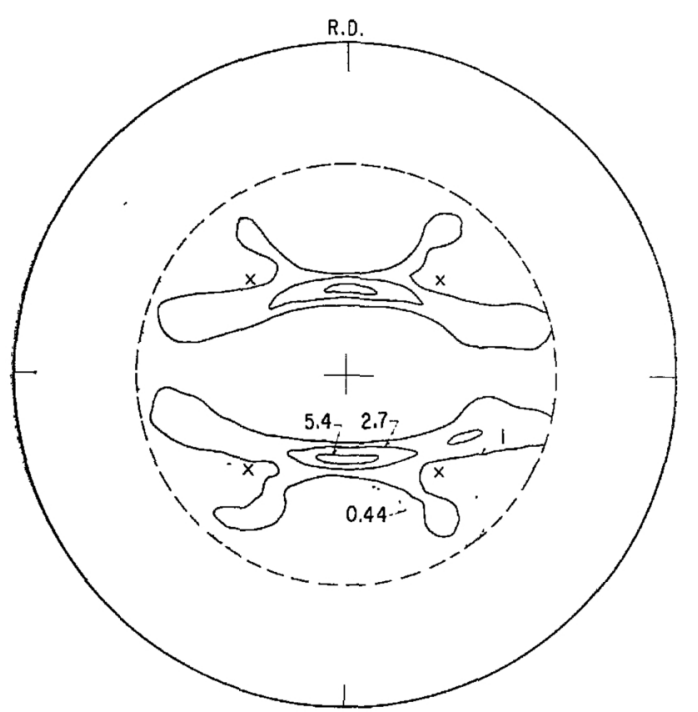

Fig. 3 (110) pole figure of a reorystallized sheet (annealed at $880^{\circ} \mathrm{C}$ for 3 hours) which was rolled from $25 \mathrm{~mm}$ to $1 \mathrm{~mm}$ in thickness. Intensities are expressed as multiples of random intensity of iron powder.

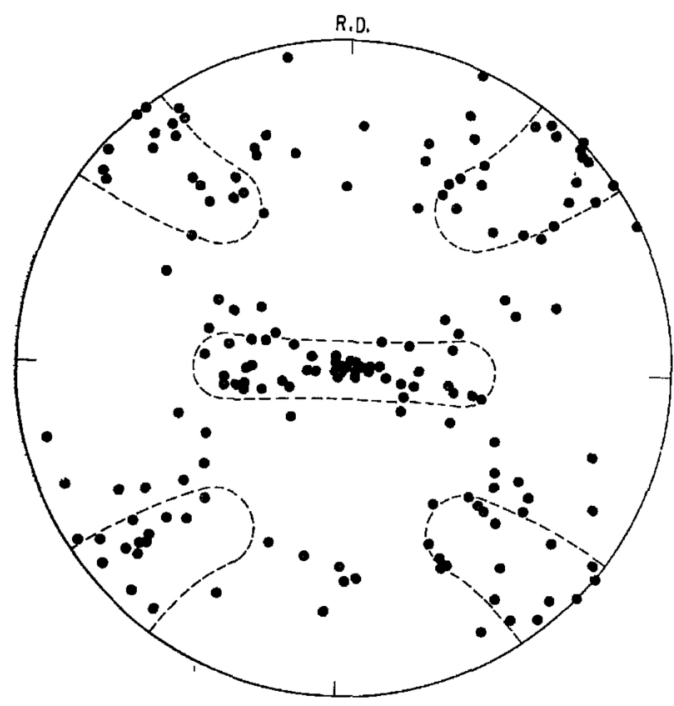

Fig. 4 Plot of (100) poles of 61 grains in a test sheet after the strain-annealing. The test sheet, which was rolled from $25 \mathrm{~mm}$ to $1 \mathrm{~mm}$ in thickness, was annealed at $850^{\circ} \mathrm{C}$ for 3 hours, strained by 4 percent and finally annealed at $850^{\circ} \mathrm{C}$ for 3 hours.

ing at $880^{\circ} \mathrm{C}$ for 3 hours in dry hydrogen. The crystal orientations of large grains in the test sheets after the strain-annealing are plotted in Fig. 4 by the $\{100\}$ poles of 61 grains. Most of the large grains $(70 \%)$ had the orientation within the region of the roll texture, as shown roughly by the dashed lines in Fig. 4.

\section{Cross Roll Method}

It can be expected from the above experiences that the (100) [011] oriented large crystals can be grown easily if the rolled sheets have the (100) [011] oriented sharp texture. Such a roll texture has been studied by $\mathrm{Hu}^{(10)}$. He produced the texture by the rollings

(10) H. Hu: Trans. AIME, 209 (1957), 1164.

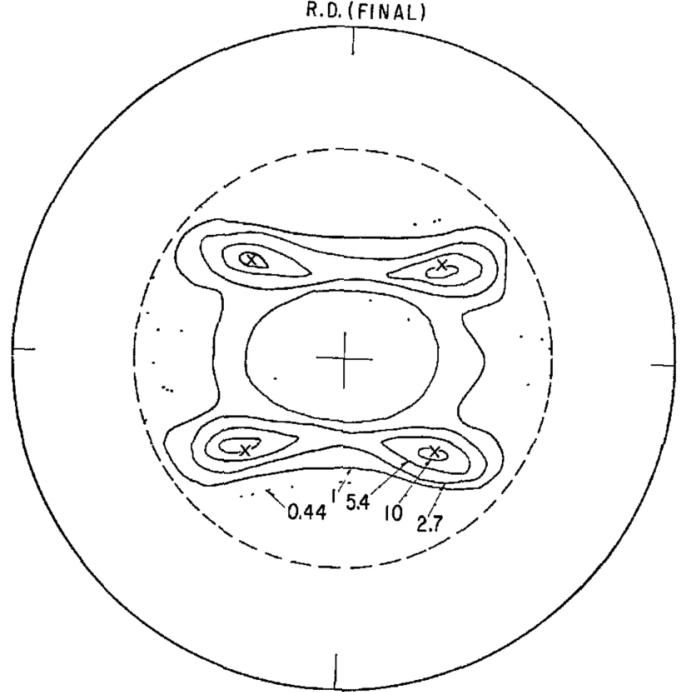

Fig. 5 (110) pole figure of a cross-rolled sheet, which was rolled from $25 \mathrm{~mm}$ to $4 \mathrm{~mm}$ and rolled in the cross direction from $4 \mathrm{~mm}$ to $1 \mathrm{~mm}$. Intensities are expressed as multiples of random intensity of iron powder.

of a sheet in two cross directions alternately. But the texture produced by this method was not very sharp. According to the experiment of Koh and Dunn (11) on the crystal rotation of silicon-iron single crystals during rolling reductions, the crystals with an orientation between (100) [011] and (211) [111] rotate into the (100) [011] orientation after about 50 percent reduction. This rotation relation suggests that the (100) [011] oriented sharp texture can be obtained by rolling a sheet, having such a roll texture as shown in Fig. 2, by about 50 percent in the direction which makes an angle of $90^{\circ}$ from the previous rolling direction.

A square sheet was cut from a sheet which was rolled from $25 \mathrm{~mm}$ to $4 \mathrm{~mm}$ in thickness. It was then cross-rolled to the thickness of $1 \mathrm{~mm}$. The crossrolled texture, as shown in Fig. 5, had the sharp (100) [011] texture as expected. The recrystallized texture after the primary annealing at $880^{\circ} \mathrm{C}$ for 3 hours is shown in Fig. 6.

The effect of the reduction ratio in the cross-rolling on the preferred orientations of large crystals in the test sheets after strain-annealing was studied. Tests were made on the sheets cross-rolled from 5 and $3 \mathrm{~mm}$ to the final thickness of $2 \mathrm{~mm}$, and 5,4 , and $2 \mathrm{~mm}$ to the final thickness of $1 \mathrm{~mm}$. Plots of $\{100\}$ poles of the large grains in the test sheets after the strainannealing show substantially a same preferred orientation in all the test sheets. An exmaple of the plot of the $\{100\}$ poles of 61 grains in a strain-annealed test sheet cross-rolled from $5 \mathrm{~mm}$ to $2 \mathrm{~mm}$ is shown in Fig. 7. Most of the large grains had the (100) [011] orientation within the range of 10 degrees as shown by dashed lines in Fig. 7. A macrophotograph of this test sheet is shown in Photo. 3. A single crystal grown in a cross-rolled sheet with a thickness of $2 \mathrm{~mm}$ is shown in Photo. 4.

(11) P.K. Koh and C.G. Dunn: Trans. ATME, 203 (1955), 401. 


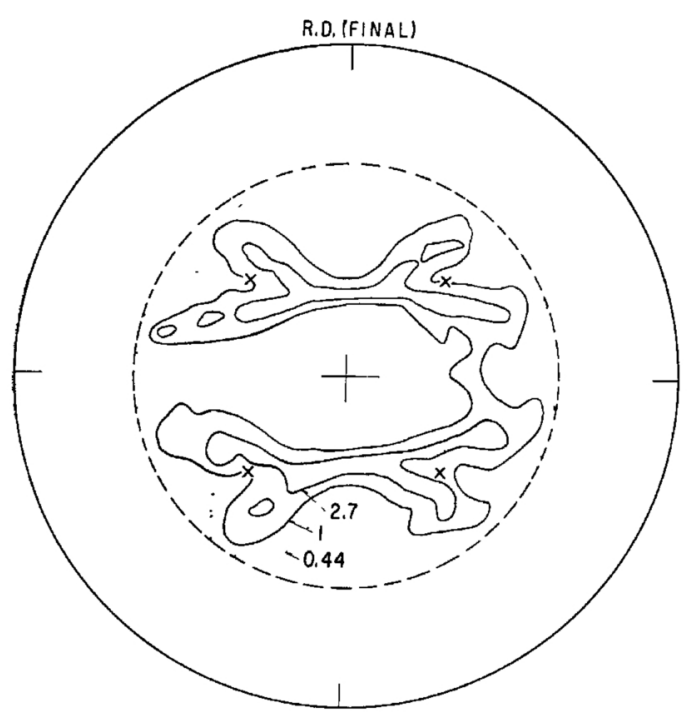

Fig. 6 (110) pole figure of a recrystallized, sheet (annealed at $880^{\circ} \mathrm{C}$ for 3 hours) which was rolled from $25 \mathrm{~mm}$ to $4 \mathrm{~mm}$ and rolled in the cross direction from $4 \mathrm{~mm}$ to $1 \mathrm{~mm}$. Intensities are expressed as multiples of random intensity of iron powder.

Because the test sheet in Photo. 3 was extended at a strain rate of $4 \times 10^{-4} \mathrm{sec}^{-1}$, the strain at which the sheet surface was covered by Lüders bands was 7.2 percent. On the other hand, the sheet for the single crystal in Photo. 4 was extended at a low strain rate of $4 \times 10^{-5} \mathrm{sec}^{-1}$, with the Lüders elongation of 4.4 percent. Edward and Pfeil(1) pointed out that the amount of strain before the final annealing is an important factor for the growth of large crystals, and that the grain size in the strain-annealed sheets is larger in the sheets with smaller strain. Such circumstances in the cross-rolled sheets will be described in the next section.

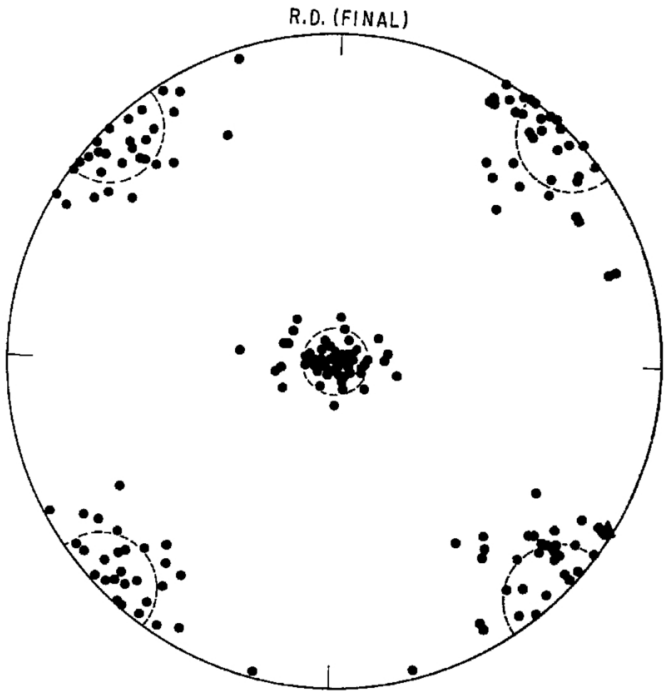

Fig. 7 Plot of (100) poles of 61 grains in a cross-rolled test sheet after strain annealing. The test sheet, which was rolled from $25 \mathrm{~mm}$ to $5 \mathrm{~mm}$ and rolled in the cross direction from $5 \mathrm{~mm}$ to $2 \mathrm{~mm}$, was annealed at $850^{\circ} \mathrm{C}$ for 3 hours, strained by 7.5 percent and finally annealed, at $850^{\circ} \mathrm{C}$ for 3 hours.

\section{Effect of the Primary Annealing Tem- perature and the Amount of Strain}

The optimum conditions of the primary annealing temperature and the amount of strain for the growth of large crystals were investigated in the cross-rolled test sheets with the size of $1.1 \times 25 \times 150 \mathrm{~mm}$ which were cross-rolled from a thickness of $4 \mathrm{~mm}$ to $1.1 \mathrm{~mm}$.

The strain before the final annealing must be introduced uniformly into the sheet. The Lüders strain in annealed high-purity iron is very large on account of the low rate of strain hardening. The relations between the Lüders elongation and the primary annealing temperature are shown in Fig. 8 at three extension

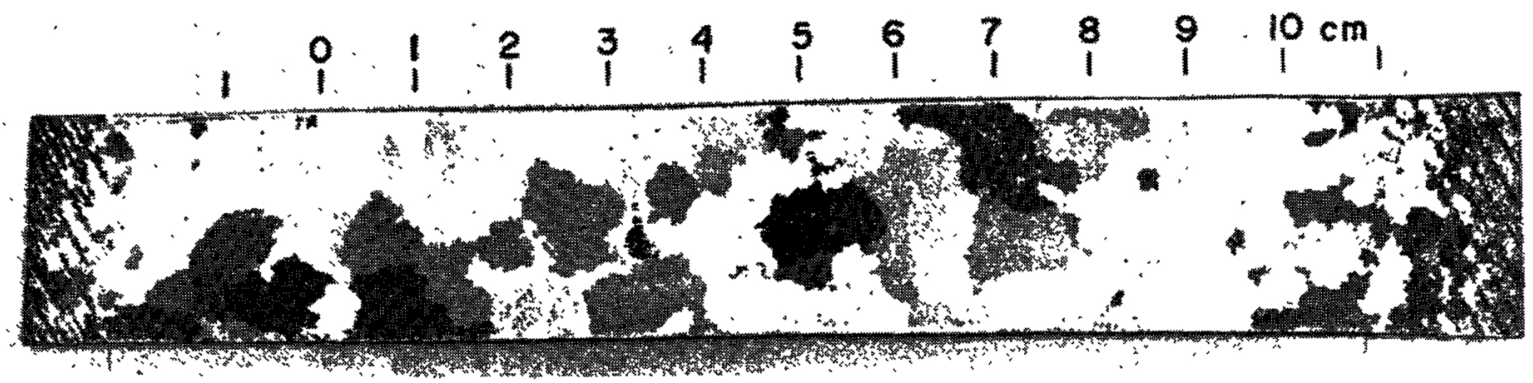

Photo. 3. A strain-annealed test sheet, which was the same sheet as in Fig. $7 . \times 1$.

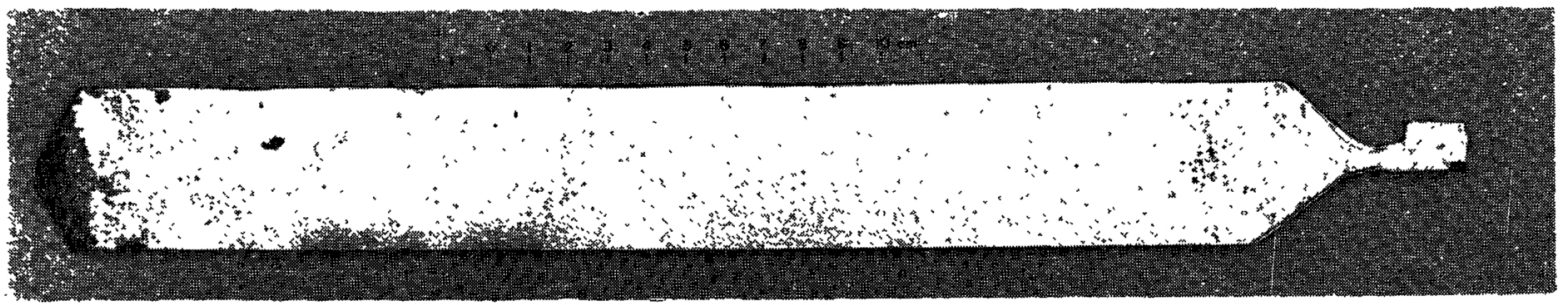

Photo. 4. An iron single crystal sheet of (100) [011] orientation, which was rolled from $25 \mathrm{~mm}$ to $5 \mathrm{~mm}$ and rolled. in the cross direction from $5 \mathrm{~mm}$ to $2 \mathrm{~mm}$, annealed at $850^{\circ} \mathrm{C}$ for 3 hours, strained by 4.4 percent, and finally annealed in the temperature gradient furnace. $\times 1 / 3$. 


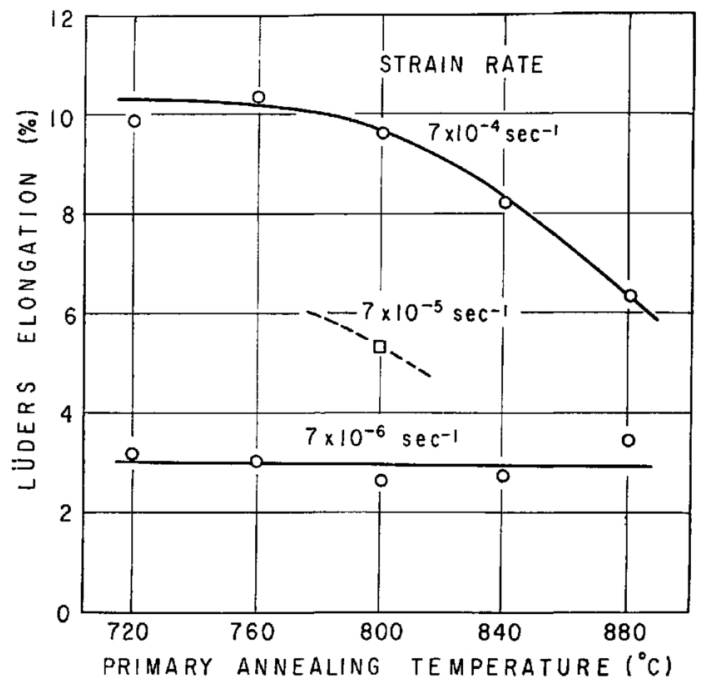

Fig. 8 The relation between Lüders elongations of cross-rolled test sheets and the primary annealing temperature at three strain rates. The test sheets were rolled from $25 \mathrm{~mm}$ to $4 \mathrm{~mm}$ and rolled in the cross direction from $4 \mathrm{~mm}$ to $1.1 \mathrm{~mm}$.

speeds. At the high strain rate $(5 \mathrm{~mm} / \mathrm{min})$ the elongations covered by the Lüders bands on the entire sheet surface became very large in the test sheets annealed at low temperature. At a low strain rate $(0.05 \mathrm{~mm} /$ $\mathrm{min}$ ) the elongations became small and was independent of the primary annealing temperature.

The grain sizes of these test sheets after the primary annealing were not uniform and the ratio of the sizes of large and small grains was about ten or more. The average grain size had increased from 40 microns at $720^{\circ} \mathrm{C}$ to 70 microns at $880^{\circ} \mathrm{C}$ with the primary annealing temperature.

The strained test sheets in Fig. 8 were annealed at $850^{\circ} \mathrm{C}$ for 3 hours in dry hydrogen. The final grain sizes after the strain-annealing are plotted in Fig. 9 by the number of grains per square centimeter as a function of the primary annealing temperature. The amount of strain in each test sheet was the Lüders elongation shown in Fig. 8. It should be noted that, although the Luiders strains in the test sheets extended at the lowest speed were independent of the primary annealing temperature, the number of grains after the final annealing decreased with increasing annealing temperature. The test sheet annealed at $880^{\circ} \mathrm{C}$ and extended at the high strain rate had a relatively large

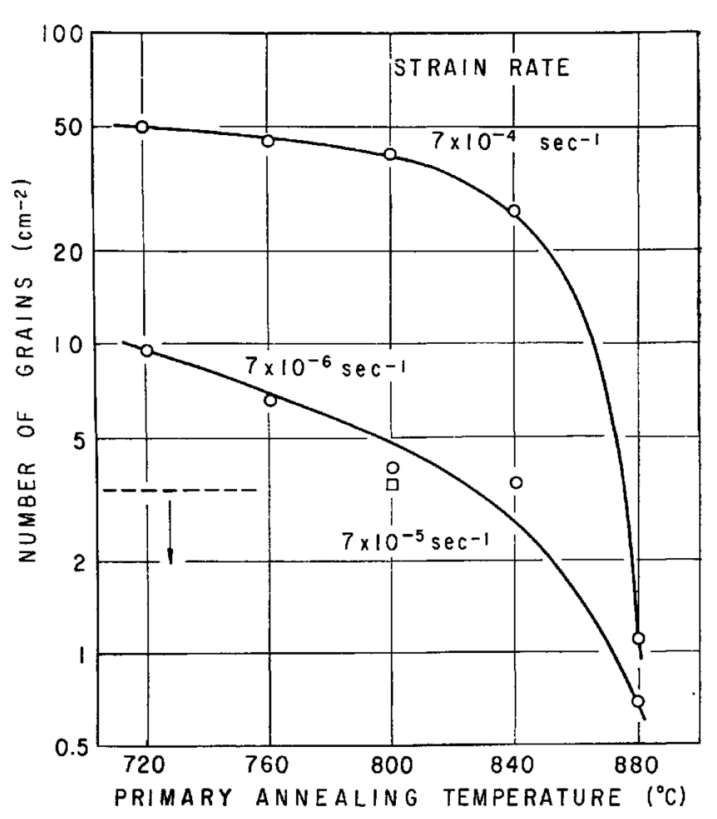

Fig. 9 Grain sizes, expressed as the number of grains per square centimeter, in the strain-annealed. test sheets as a function of the primary annealing temperature and the strain rates. The test sheets were the same as in Fig. 8. The amount of strain in each test sheet is shown in Fig. 8.

Lüders elongation (6 percent), but its grain size after the final annealing was sufficiently large.

Many experiences in this investigation suggested that the number of grains in the test sheets after the final annealing must be, as a necessary condition for the growth of large crystals in the temperature gradient. furnace, smaller than about 3 grains per square centimeter as shown by an arrow in Fig. 9. Therefore the optimum amount of strain before the final annealing must be determined in connection with the primary annealing temperature and the strain rate.

The probability of success for the growth of large crystals in the temperature gradient furnace became higher in the sheets annealed at high temperature and strained at a low strain rate, but the island grains left on the sheet surface increased in number and size. Because the number of island grains left on the sheet. surface scattered from one sheet to another and even in one sheet, the quantitative expression was impossible. Some crystals with the (100) [011] orientation was

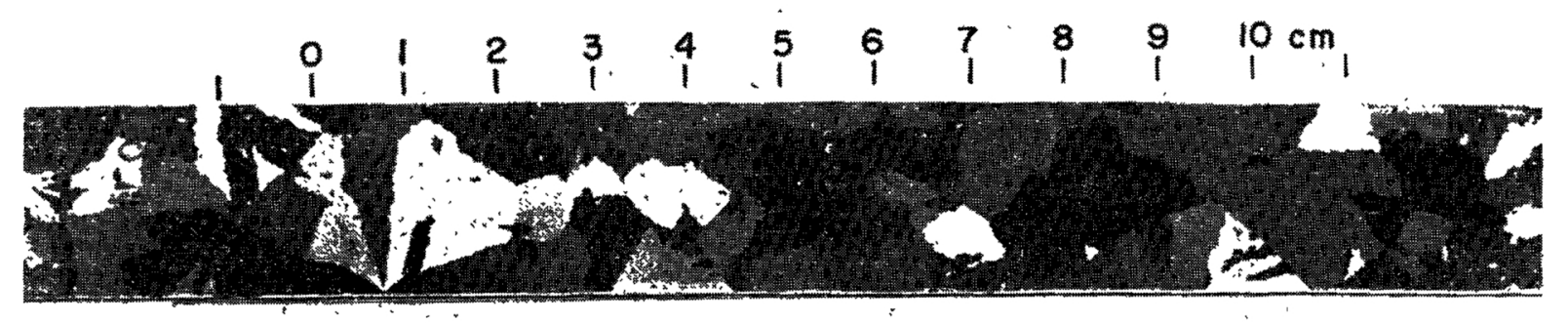

Photo. 5 A strain-annealed test sheet, which was rolled from $25 \mathrm{~mm}$ to $1 \mathrm{~mm}$, in which the intermediate anneals $\left(800^{\circ} \mathrm{C}\right.$ for $\left.30 \mathrm{~min}\right)$ were inserted at the thickness of 12,6 , and $3 \mathrm{~mm}$. The sheet was annealed at $780^{\circ} \mathrm{C}$ for 3 hours, strained by 5 percent and finally annealed at $850^{\circ} \mathrm{C}$ for 3 hours $\times 1$. 
almost free from the island grains, less than one island grain per square centimeter on the whole crystal surfaces.

The optimum conditions for the primary annealing temperature, the amount of strain and the strain rate must be selected in consideration of the two opposing factors, in order to increase the probability of success for the growth of large crystal, and to minimize the number of island grains left on the sheet surface. Accordingly, the following procedure has been adopted: (1) The cross-rolled sheets are annealed at $840^{\circ} \mathrm{C}$ for 3 hours and strained at a rate of $4 \times 10^{-5} \mathrm{sec}^{-1}$ (1 $\mathrm{mm} / \mathrm{min}$ for the sheet of $400 \mathrm{~mm}$ in length) by about 4 percent, or (2) The cross-rolled sheets are annealed at $880^{\circ} \mathrm{C}$ for 3 hours and strained at a rate of $1.2 \times 10^{-4}$ $\mathrm{sec}^{-1}$ by about 5 percent.

\section{Trials for the Other Orientations}

The results of the preceding sections showed that the large crystals of the orientations other than the (100) [011] almost free from island grains could not grow in the sheets produced by the high reduction method or the cross-roll method. Therefore, the trials were made with an effort to make roll textures different from those in the preceding sections.

\section{Many intermediate anneals during rolling reduction}

Starting from a slab $25 \mathrm{~mm}$ in thickness, many intermediate anneals at $800^{\circ} \mathrm{C}$ for $30 \mathrm{~min}$ in hydrogen were inserted in the course of the rolling process, at the thickness of 12,6 , and $3 \mathrm{~mm}$, respectively, and rolled up to $1 \mathrm{~mm}$. A macrophtograph of a test sheet, annelaed at $780^{\circ} \mathrm{C}$, strained by 4.5 percent and finally annealed at $850^{\circ} \mathrm{C}$ for 3 hours is shown in Photo. 5 . The primary annealing of the rolled sheets above $800^{\circ} \mathrm{C}$ gave large recrystallized grains of the order of $1 \mathrm{~mm}$ in the largest. Many of large crystals in the test sheets shown in Photo. 5 had the orientations near the (111) [011]. And the shapes of these grains were different from those in the sheets produced by high reduction (Photo. 1) and cross-rolling (Photo. 3).

Although the diameters of large grains in Photo. 5 were about $2 \sim 1 \mathrm{~cm}$, the large crystals grown in the temperature gradient furance were mostly elongated grains with the breadth of $10 \sim 15 \mathrm{~mm}$, and they had may fine island grains left on the crystal surface.

\section{Annealing in the $\gamma$ phase}

The process for the growth of large crystals with any desired orientation proposed by Stein and Low ${ }^{(7)}$ has employed an annealing above the $\alpha-\gamma$ transformation temperature before the final cold rolling.

The sheets with several thicknesses of $2 \sim 5 \mathrm{~mm}$ were quenched from $950^{\circ} \mathrm{C}$ rapidly into ice-water, and rolled to the thickness of $1 \mathrm{~mm}$. The test sheets cut from them were annealed at $740^{\circ} \mathrm{C}, 780^{\circ} \mathrm{C}$ and $820^{\circ} \mathrm{C}$, and strained by about 4 percent, and finally annealed at $850^{\circ} \mathrm{C}$. The grain sizes of all the test sheets after the strain-annealing were less than $10 \mathrm{~mm}$ and many island grains reexamined on the surface even in the test sheets primarily annealed at $740^{\circ} \mathrm{C}$.

The process to make large crystals with the orienta- tions other than (100) [011], free from island grains, could not be found in the iron used for the present investigation.

\section{Discussion}

Because the recrystallization characteristic in metals is very sensitive to the impurities contained in the material, the applicability of the present results to high-purity iron with different impurity contents is uncertain in the scope of the present results. There has been another experience on the growth of large single crystal sheets from a slightly impure iron (12), which contained 0.08 percent manganese to improve ductility at room temperature. The preferred orientation of single crystals grown from this material had the borad (110) [001] texture. The strain-anneal characteristic in this material was similar to that of iron used by Edward and Pfeil(1), entirely different from the present iron. Preferred orientations of large grains in strain-annealed sheets of another iron, as reported by Murata and Dohi(13), had also the broad (110) [001] texture. Large crystals having this orientation did not grow in the present iron. A distinct difference between the present iron and the iron containning 0.08 percent manganese was observed in the grain structures after the primary annealing of the rolled sheets. The grain structures of the former were unstable and non-uniform, and the latter were very stable, fine, and uniform. The procedure developed by Stein and Low ${ }^{(7)}$ on the Ferrovac E iron could not be applied to the present iron. A casue for the failure seemed to be due to the difference in the small amount of metallic impurities.

Some plastic properties observed in the iron single crystals prepared from the present large crystals has been reported elsewhere. (14),(15)

\section{Summary}

(1) The effect of the roll textures on the growth of the large crystals by the strain-anneal technique has been investigated on a high purity electrolytic iron.

(2) The preferred orientations of large grains grown by the strain annealing technique were approximately the same as the roll textures.

(3) The large crystals free from island grains left on the sheet surface had the (100) plane in the sheet surfaces.

(4) The sharp (100) [011] roll texture was obtained by the cross rolling in the final stage of rolling process.

(5) Large single crystal sheets with the (100) [001] orientation grew easily in the cross-rolled sheets with the thickness of $2 \mathrm{~mm}$ or $1 \mathrm{~mm}$.

(6) Attempts to grow crystals with the orientations other than (100) [011] free from island grains ended

(12) T. Takeuchi and S. Ikeda: J. Phys Soc. Japan, 18 (1963), 1841.

(13) A. Murata and S. Dohi: J. Japan Inst. Metals, 25 (1961), 324.

(14) T. Takeuchi: J. Phys. Soc. Japan, 20 (1965), 942.

(15) S. Tkeda and T. Takeuchi: J. Phys. Soc. Japan, 20 (1965), 2152. 
in a failure.

\section{Acknowledgements}

bayashi and J. Imamura for their helpful discussions. $\mathrm{He}$ is also indebted to $\mathrm{K}$. Iwayama for measuring the data in Fig. 8 and to M. Uehara for his assistance in the early period of this investigation. 